\title{
Effect of macroscopic grooves on bone formation and osteoblastic differentiation
}

AUTHORS: Kenji Miyahara DDS*, Takao Watamoto DDS, PhD**, Yusuke Uto DDS***, Takashi Sawase DDS, PhD\#

\section{ABSTRACT (183 words)}

Objectives: The aim of this study is to investigate the effect of macroscopic grooves on bone formation in vivo and differentiation of human mesenchymal stem cells (hMSCs) in vitro.

Materials and methods: The effects of macroscopic grooves on titanium alloy implants and disks were tested in rabbit tibiae and cultured hMSCs. The bone-to-implant contact (BIC) and bone area were evaluated in rabbit tibiae at 6 and 24 weeks after implant insertion. Osteoblastic differentiation was assessed by alkaline phosphatase (ALP) activity and real-time reverse-transcription polymerase chain reaction (RT-PCR) on Days 7, 14 and 21. All values were statically analyzed.

Results: BIC and bone area inside the grooves were significantly higher than those of control implants $(P<0.05)$. ALP activity was significantly higher for titanium disks with macroscopic grooves than without grooves on Day $14(P<0.05)$. Real-time RT-PCR showed that the expression of osteogenic genes was significantly higher for disks with grooves on Day $7(P<0.01)$.

Conclusions: Macroscopic grooves accelerate osteoblastic differentiation in vitro and stimulate direct bone growth and deposition within the grooves in vivo.

KEY WORDS: dental implant, human mesenchymal stem cell, rabbit tibia, bone formation

* Postgraduate Student, Dept. of Applied Prosthodontics, Graduate School of Biomedical Sciences, Nagasaki University, Japan

** Assistant Professor, Dept. of Applied Prosthodontics, Graduate School of Biomedical Sciences, Nagasaki University, Japan

${ }^{* * *}$ Postgraduate Student, Dept. of Applied Prosthodontics, Graduate School of Biomedical Sciences, Nagasaki University,

\# Professor and Chair, Dept. of Applied Prosthodontics, Graduate School of Biomedical Sciences, Nagasaki University, Japan

Reprint requests and correspondence to: Takao Watamoto, DDS, PhD, Dept. of Applied Prosthodontics, Graduate School of Biomedical Sciences, Nagasaki University, 1-7-1 Sakamoto, Nagasaki 852-8588, Japan 
Implant design is one of the crucial factors to achieve and maintain osseointegration ${ }^{1}$. The screw shape implant design is clinically dominated since it is easy to install into the bone bed and achieve primary fixation. It has been reported that axial or rotational mobility at implant placement leads to a significantly reduced amount of bone around the implants or a higher failure rate ${ }^{2,3}$. Thus, it is generally accepted that good stability at the implant placement is highly desirable. Screw shape design and/or tapered configuration of the implant can be readily-stabilized and easily-controlled by clock wise tightening.

Implant design also contribute to obtaining secondary stability. Since osseointegrated implants transfer the chewing forces to the bone tissue, implant design plays an important role for the load distribution or concentration. It is well known that the bone adapts to the mechanical loading. The proper load can stimulate the bone tissue, resulting in a changed bone structure and volume ${ }^{4}$. On the other hand, when bone tissue is subjected to unphysiologically high stress, fracture or bone resorption may occur ${ }^{5}$. Finite element analysis has revealed the highest stress at the coronal portion of the bone and implant interface ${ }^{6}$. Since,

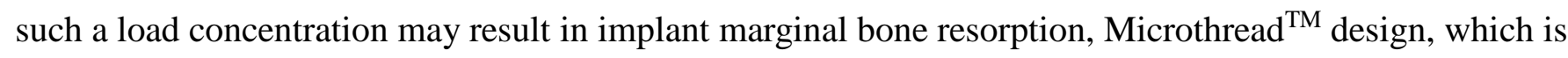
suitable for screw shaped implants, can distribute the stress evenly and maintain marginal bone level, has been applied to the implant neck ${ }^{7}$. Indeed, in a 3-year prospective clinical study, two types of screw implants with and without Microthread ${ }^{\mathrm{TM}}$ of $220 \mu \mathrm{m}$ width were installed adjacent to each other within the same partially edentulous site. The marginal bone level has been well maintained on the implant with Microthread $^{\mathrm{TM}}$ configuration $^{8}$. Therefore, not only loading conditions but also the surface macro architectures can enhance bone apposition around implant neck region. Furthermore, viewed in the stress distribution and screw shaped implant design, thread or groove configurations are optimal surface macro architectures of implant.

From the studies of bone substitutes, the pore size influence on the vascularization and bone apposition into the pores. The average pore size of 210 to $280 \mu \mathrm{m}$ showed the migration of mesenchymal stem cells into the pores in conjunction with vascular invasion, then followed by intramembranous ossification ${ }^{9,10}$. Hall et $\mathrm{al}^{11}$ has also focused on 50 to $200 \mu \mathrm{m}$ range of implant surface structure, which are between the sizes of typical thread geometries and surface topographies. Such structure have often been investigated on 
threaded dental implant and the grooves in these range were defined as macroscopic groove ${ }^{11}$. The grooves with either $110 \mu \mathrm{m}$ width / $70 \mu \mathrm{m}$ depth or $200 \mu \mathrm{m}$ width / $70 \mu \mathrm{m}$ depth at a thread frank of screw shaped implant have been installed in the rabbit tibiae. Nevertheless, both groove showed significantly higher histomorphometric results than control implants, the biomechanical testing revealed significantly higher resistance to removal torque for the $110 \mu \mathrm{m}$ groove but not for the $200 \mu \mathrm{m}$ groove. It is speculated that the depth of the groove $(70 \mu \mathrm{m})$ was relatively shallow to provide an enough interlocking force for $200 \mu \mathrm{m}$ groove. It can be curious rather deeper groove may enhance bone apposition and blood capillary invasion into the groove. Taken together, it is hypothesized that bone formation and vascularization with migration of mesenchymal stem cells are enhanced and bone remodeling are maintained in macroscopic grooves with $200 \mu \mathrm{m}$ in width and depth. However, little is known about the effect of the macroscopic groove on bone formation and cell differentiation.

The aim of the current study is to confirm the enhanced bone formation within the macroscopic grooves than conventional flat area in vivo, subsequently to investigate the effect of macroscopic grooves on differentiation of human mesenchymal stem cells (hMSCs).

\section{MATERIALS AND METHODS}

Implant preparation

In this study, we used 28 screw-shaped commercially available Grade 5 titanium alloy (Ti-6Al-4V) implants. Implants were $6 \mathrm{~mm}$ in length and $3.7 \mathrm{~mm}$ in diameter. All implant surfaces were sandblasted with aluminium oxide powder and subjected to anodic oxidation in phosphoric acid solution. Fourteen implants were used as controls and 14 implants with grooves $200 \mu \mathrm{m}$ wide and $200 \mu \mathrm{m}$ deep on the collar of the implant surface were used as experimental implants (Fig. 1a, e).

Animal experiments

Fourteen adult female Japanese white rabbits (average body weight: $4 \mathrm{~kg}$; age: 7-9 months) were used for the animal experiments. Animal care and experimental procedures were performed in accordance with the 
guidelines for animal experimentation of Nagasaki University, Nagasaki, Japan, with the approval of the Ethics Review Committee for Animal Experimentation of Nagasaki University. Prior to the surgery, animals were anaesthetized with intramuscular injections of ketamine $(0.5 \mathrm{mg} / \mathrm{kg})$ and xylazine $(0.25$ $\mathrm{mg} / \mathrm{kg}$ ) and locally anaesthetized with lidocaine. The skin and fascial-periosteal layers were opened separately. Rotary drill speeds did not exceed 2,000 rpm and saline cooling was used during all surgical drilling sequences. Each rabbit received a control and experimental implant unicortically in the right and left proximal tibial metaphyses. Both types of implant were evenly distributed in the left and right tibiae. After 6 and 24 weeks of healing, 7 rabbits per healing period were sacrificed by intravenous injection of pentobarbital. Implants were removed en bloc and immersed in a fixative and increasing grades of ethanol. Finally, bone blocks were embedded in methyl methacrylate resin and one central section per implant was prepared. Sections were ground to a final thickness of approximately $20 \mu \mathrm{m}$ and stained with toluidine blue. The percentage BIC was calculated for the collar portion of the implant (Fig. 1b, f). The percentage bone area was calculated for the rectangular area $200 \mu \mathrm{m}$ from the implant surface (Fig. 1c, g).

\section{Titanium disks}

Titanium disks were manufactured from commercially available Grade 5 titanium alloy (Ti-6Al-4V). The disks (Fig. 1d), $1 \mathrm{~mm}$ in thickness and $20 \mathrm{~mm}$ in diameter, with and without macroscopic grooves in order to fit the wells of a 12-well cell-culture plate (Iwaki Co., Ltd., Tokyo, Japan). Macroscopic grooves were $200 \mu \mathrm{m}$ in width and $200 \mu \mathrm{m}$ in depth (Fig. 1h). All titanium disk surfaces were sandblasted and subjected to anodic oxidation under the same conditions as used for implant preparation. The average surface roughness (Ra) of each disk was $1.46 \mu \mathrm{m}$. After surface treatment, all disks were ultrasonically cleaned in acetone and ethanol and sterilized using ethylene dioxide gas.

\section{Cell culture}

Early-passage populations of human mesenchymal stem cells (hMSCs) were obtained from commercial sources (118529; Lonza Group, Basel, Switzerland). Cells were allowed to grow in $\alpha$-minimum essential medium ( $\alpha$-MEM) supplemented with 15\% (v/v) foetal bovine serum (FBS) and 1\% antibiotic-antimycotic solution (all culture media were purchased from Sigma-Aldrich Corporation, St. Louis, MO, USA). Cells 
were maintained under standard culture conditions $\left(37^{\circ} \mathrm{C}\right.$ in a $5 \% \mathrm{CO}_{2}$ humidified atmosphere). Culture medium was changed every 2 days until confluence was achieved. Cells were seeded at a density of $1 \times$ $10^{5}$ cells/mL into 12-well plates containing titanium disks with or without macroscopic grooves. After $3 \mathrm{~h}$, unattached cells were removed with phosphate-buffered saline and $\alpha$-MEM with $15 \%$ FBS, $10^{-7} \mathrm{M}$ dexamethasone, $1 \mathrm{M} \beta$-glycerophosphate and $5 \mathrm{mg} / \mathrm{mL}$ ascorbic acid were added for osteoblastic differentiation.

Alkaline phosphatase (ALP) activity

Cells were seeded onto titanium disks with or without grooves at $5 \times 10^{4}$ cells/well in osteoblastic medium. ALP activity was measured after incubation at 7 and 14 days and quantified using TRACP and ALP assay kits (Takara Bio., Inc., Shiga, Japan). Absorbance was measured at $405 \mathrm{~nm}$ using a microplate reader and enzyme activity was expressed as $\mu \mathrm{U} / \mu \mathrm{L}$.

RNA extraction, cDNA synthesis and quantitative real-time polymerase chain reaction (PCR) After incubation for 7, 14 and 21 days, total RNA was extracted from cultured cells using the SV total RNA isolation system (Promega Corporation, Madison, WI, USA) according to the manufacturer's instructions. RNA purity and integrity were determined using a NanoDrop ND-1000 spectrophotometer (NanoDrop Technologies, Inc., Wilmington, DE, USA). Furthermore, gel electrophoresis was performed to verify whether RNA was intact. cDNA was synthesized from $2 \mu \mathrm{g}$ of GoScript ${ }^{\mathrm{TM}}$ Reverse Transcription System (Promega Corporation). For the quantitative analysis of gene expression, mRNA levels were measured using quantitative real-time reverse-transcription PCR (RT-PCR). The primers (Hoffmann-La Roche AG, Basel, Switzerland) used for this assay are listed in Table 1. Quantitative RT-PCR was performed on an ABI PRISM ${ }^{\circledR} 7900 H T$ (Applied Biosystems, Foster City, CA, USA) sequence detection system using SYBR $^{\circledR}$ green incorporation (SYBR ${ }^{\circledR}$ Green PCR Master Mix; Applied Biosystems) in duplicates for at least three independent experiments. Fluorescence intensities were quantified with StepOne ${ }^{\mathrm{TM}}$ Software (Applied Biosystems). The relative quantities of target genes were normalized against the expression of the housekeeping gene ACT1 and analyzed using the comparative $\Delta \Delta \mathrm{Ct}$ method while considering amplification efficiency ${ }^{12}$. 


\section{Statistical analysis}

The statistical analysis of ALP activity and gene expression with or without grooves was performed with the Student's $t$-test $(P=0.05)$ using IBM SPSS Statistics 22.1 (IBM Corporation, Armonk, NY, USA). The statistical analyses of BIC and bone area in control and experimental implants were performed using the Bonferroni multiple comparison test $(P=0.05)$ also using IBM SPSS Statistics 22.1. To clarify whether there was a significant enhancement in bone formation within the grooves, the analysis of experimental implants was divided into flat area and grooves.

\section{RESULTS}

\section{Histomorphometric analysis}

Light microscopy demonstrated that woven bone formation after 6 weeks of healing was sufficient to fill the collar portion of the implant (Fig. 2a, b). Newly formed bone was observed extending into the groove structures (Fig. 2b). At 6 weeks, the mean and standard deviation (SD) of the percentage BIC was $43.3 \pm$ $12.1 \%$ for control implants, $35.6 \pm 9.3 \%$ for the flat areas of experimental implants and $49.5 \pm 11.1 \%$ for the grooves of experimental implants (Fig. 3). BIC was significantly higher in the grooves than in the flat areas of experimental implants $(P<0.05)$. The mean and SD of the percentage bone area was $60.7 \pm 11.8 \%$ for control implants, $65.9 \pm 10.7 \%$ for the flat areas of experimental implants and $76.9 \pm 5.4 \%$ for the grooves of experimental implants (Fig. 4). The bone area was significantly higher in the grooves of experimental implants than control implants $(P<0.05)$. At 24 weeks, all implants were well integrated and had established intimate contact with lamellar bone (Fig. 2c, d). The percentage BIC was $51.2 \pm 9.9 \%$ for control implants, $40.4 \pm 7.1 \%$ for the flat areas of experimental implants and $63.1 \pm 8.8 \%$ for the grooves of experimental implants (Fig. 3). BIC was significantly higher for the grooves of experimental implants than control implants or the flat areas of experimental implants $(P<0.05)$. The percentage bone area was $58 \pm 6.9 \%$ for control implants, $54.7 \pm 11.4 \%$ for the flat areas of experimental implants and $67.3 \pm 7.3 \%$ for the grooves of experimental implants (Fig. 4). The bone area was significantly higher for the grooves of experimental implants than control implants and the flat areas of experimental implants $(P<0.05)$. 
Mature bone formation and remodelling were evident within the grooves and living bone was filled within the almost grooves (Fig. 2d).

\section{Analysis of differentiation ability}

To evaluate the effect of macroscopic grooves on osteoblastic differentiation, real-time RT-PCR and ALP assays were performed for each group. Results of ALP activity are presented in Fig. 5. ALP activity on Day 14 was significantly higher for titanium disks with macroscopic grooves than that without grooves $(P<$ $0.05)$.

Real-time RT-PCR results are presented in Fig. 6. On Day 7, the expression of osteopontin (OPN), osteocalcin (OCN), type 1 collagen (Col1) and ALP for titanium disks with macroscopic grooves was significantly higher than that without grooves $(P<0.01$; OPN, 1.76-fold; OCN, 3.08-fold; Col1, 2.29-fold; and $A L P, 3.40$-fold). On Day 14, no statistically significant differences were evident for all genes assessed. On Day 21, the expression of $O C N$, Col1 and $A L P$ for titanium disks with macroscopic grooves was significantly higher than that without grooves $(P<0.01$ for $O C N, 1.61$-fold; $P<0.05$ for Col1, 1.54-fold; $P<0.05$ for $A L P, 1.58$-fold).

\section{DISCUSSION}

Osseointegration is a wound healing process involving numerous cellular and extracellular events ${ }^{13}$, which reflects the structural and functional connection between living bone and the implant surface. In this study, we investigated the effects of macroscopic grooves on bone formation around titanium implants in vivo and on hMSCs cultured on titanium disks in vitro.

To clarify the effects of macroscopic grooves on bone formation in vivo, we performed animal experiments. We evaluated BIC and bone area in rabbits based on a previous study ${ }^{14}$. BIC, the parameter evaluated most often in in vivo studies ${ }^{15}$, and bone area were measured at 6 and 24 weeks after implant insertion. According to an earlier study ${ }^{16}$, a 6 -week healing period in rabbits 
is insufficient for mature bone formation, whereas a 24-week healing period is sufficient for mature bone formation and acquiring secondary fixation between bone and implant. At implant insertion, macroscopic grooves were filled with blood clots not with bone, because experimental implants were screwed into bone bed which was same as implant body size. At 6 weeks, greater new bone formation and extension were evident within the macroscopic grooves than in the flat area of the implant surface. These observations were enhanced at 24 weeks, BIC and bone area were significantly increased within the macroscopic grooves. These results demonstrated that the wide and deep macroscopic grooves could promote new bone formation and maintain bone remodelling with the vascularization. Growth of the bone matrix into the grooves enables implants to interlock mechanically with the surrounding bone formation. Therefore, the use of macroscopic grooves could promote rapid bone formation around implant and contribute firm osseointegration. .

Cell culture studies allow the detailed evaluation of cell and matrix interactions with artificial material surfaces ${ }^{17}$. hMSCs can self-renew and differentiate into precursors cells, including osteoprogenitors ${ }^{18}$. Osteoprogenitors play a central role in the osseointegration process, including bone remodelling and repair. Contact between osteoprogenitor cells and the implant surface is the first step of bone formation and the basis for subsequent events, which include the deposition of an organized extracellular matrix and its mineralization. Properties of the implant surface, including wettability, texture, chemical composition, surface topography and roughness, directly influence cell proliferation and differentiation, extracellular matrix synthesis and the local production of factors ${ }^{19-24}$. Therefore, to clarify the direct effects of macroscopic grooves on osteoblastic differentiation of hMSCs in vitro, we also performed cell culture experiment.

ALP, an early marker of osteogenic differentiation, is found in high levels in cells that mineralize their extracellular matrix ${ }^{25}$, and osteoblasts produce ALP activity enriched extracellular matrix vesicles during maturation. OCN, a late differentiation marker, is synthesized by osteoblasts and is an indicator of the formation and maturation of mineralized tissue. OPN and Col1, osteoblastic differentiation markers, 
encode bone matrix proteins. In this study, the expression of osteoblastic differentiation marker genes was significantly increased on Day 7 in cells cultured on titanium disks with macroscopic grooves. ALP activity increased on Day 14 in cells cultured on titanium disks with macroscopic grooves compared with those without grooves. However, on Day 14, there was no difference in the expression of the genes assessed in this study between cells cultured on titanium disks with and without grooves, suggesting that gene expression in cells cultured on disks without grooves had 'caught up' with that in cells cultured on disks with grooves. On Day 21, the expression of the genes assessed in this study was slightly increased in cells cultured on disks with grooves and remained higher than in cells cultured on disks without grooves. These results imply that macroscopic grooves may activate cell-cell communication by providing hMSCs with a three-dimensional scaffold, increasing the density of hMSC secretions and accelerating the expression of osteoblastic differentiation marker genes ${ }^{11,26}$. This could allow hMSCs cultured on titanium disks with macroscopic grooves to differentiate into osteoblast and mineralize their extracellular matrix rapidly. Therefore, a surface design featuring macroscopic grooves is suitable for osteoblastic differentiation of hMSCs and may contribute to rapid bone formation.

\section{CONCLUSION}

Macroscopic grooves accelerate osteoblastic differentiation in vitro and stimulate directed bone growth and deposition within grooves in vivo. These results suggest that macroscopic grooves provide an excellent environment for cell differentiation, bone formation and remodelling. This study has some limitations; only osteoblastic differentiation was evaluated and the rabbit tibia is not an entirely relevant model for dental implants in terms of clinical function. However, this study provides insight into simple features of implant design that may optimize implant stability and improve long-term prognosis.

\section{DISCLOSURE}

The authors claim to have no financial interest, either directly or indirectly, in the products or information listed in this article. 


\section{ACKNOWLEDGEMENTS}

This work was supported by a Grant-in-Aid for Scientific Research (B 22390368) from the Japan Society of the Promotion of Science. Titanium disks and implants were provided by KYOCERA Medical Corporation (Osaka, Japan). 


\section{REFERENCES}

1. Albrektsson T, Branemark PI, Hansson HA et al. Osseointegrated titanium implants. Requirements for ensuring a long-lasting, direct bone-to-implant anchorage in man. Acta orthopaedica Scandinavica 1981; 52: 155-70.

2. Ivanoff CJ, Sennerby L, Lekholm U. Influence of initial implant mobility on the integration of titanium implants. An experimental study in rabbits. Clinical oral implants research 1996; 7: 120-7.

3. Orenstein IH, Tarnow DP, Morris HF et al. Factors affecting implant mobility at placement and integration of mobile implants at uncovering. Journal of periodontology 1998; 69: $1404-12$.

4. Frost HM. Wolff's Law and bone's structural adaptations to mechanical usage: an overview for clinicians. The Angle orthodontist 1994; 64: 175-88.

5. Hoshaw SJ, Cody DD, Saad AM et al. Decrease in canine proximal femoral ultimate strength and stiffness due to fatigue damage. Journal of biomechanics 1997; 30: 323-9.

6. Kitamura E, Stegaroiu R, Nomura S et al. Biomechanical aspects of marginal bone resorption around osseointegrated implants: considerations based on a three-dimensional finite element analysis. Clinical oral implants research 2004; 15: 401-12.

7. Hansson S. The implant neck: smooth or provided with retention elements. A biomechanical approach. Clinical oral implants research 1999; 10: 394-405.

8. Lee DW, Choi YS, Park KH et al. Effect of microthread on the maintenance of marginal bone level: a 3-year prospective study. Clinical oral implants research 2007; 18: 46570.

9. Klenke FM, Liu Y, Yuan H et al. Impact of pore size on the vascularization and osseointegration of ceramic bone substitutes in vivo. Journal of biomedical materials research Part A 2008; 85: 777-86.

10. Karageorgiou V, Kaplan D. Porosity of 3D biomaterial scaffolds and osteogenesis. Biomaterials 2005; 26: 5474-91.

11. Hall J, Miranda-Burgos P, Sennerby L. Stimulation of directed bone growth at oxidized titanium implants by macroscopic grooves: an in vivo study. Clinical implant dentistry and related research 2005; 7 Suppl 1: S76-82.

12. Pfaffl MW. A new mathematical model for relative quantification in real-time RTPCR. Nucleic acids research 2001; 29: e45.

13. Ivanovski S, Hamlet S, Salvi GE et al. Transcriptional profiling of osseointegration in humans. Clinical oral implants research 2011; 22: 373-81.

14. Jimbo R, Xue Y, Hayashi M et al. Genetic responses to nanostructured calciumphosphate-coated implants. Journal of dental research 2011; 90: 1422-7.

15. Al-Hamdan $\mathrm{K}, \mathrm{Al}$-Moaber $\mathrm{SH}$, Junker $\mathrm{R}$ et al. Effect of implant surface properties on peri-implant bone healing: a histological and histomorphometric study in dogs. Clinical oral implants research 2011; 22: 399-405.

16. Roberts WE, Smith RK, Zilberman Y et al. Osseous adaptation to continuous loading of rigid endosseous implants. American journal of orthodontics 1984; 86: 95-111.

17. Cooper LF, Masuda T, Whitson SW et al. Formation of mineralizing osteoblast 
cultures on machined, titanium oxide grit-blasted, and plasma-sprayed titanium surfaces. The International journal of oral \& maxillofacial implants 1999; 14: 37-47.

18. Eskildsen T, Taipaleenmaki H, Stenvang $J$ et al. MicroRNA-138 regulates osteogenic differentiation of human stromal (mesenchymal) stem cells in vivo. Proceedings of the National Academy of Sciences of the United States of America 2011; 108: 6139-44.

19. Anselme K, Bigerelle M. Topography effects of pure titanium substrates on human osteoblast long-term adhesion. Acta biomaterialia 2005; 1: 211-22.

20. Deligianni DD, Katsala N, Ladas S et al. Effect of surface roughness of the titanium alloy $\mathrm{Ti}-6 \mathrm{Al}-4 \mathrm{~V}$ on human bone marrow cell response and on protein adsorption. Biomaterials 2001; 22: 1241-51.

21. Elias CN, Meirelles L. Improving osseointegration of dental implants. Expert review of medical devices 2010; 7: 241-56.

22. Lamers E, Walboomers XF, Domanski M et al. The influence of nanoscale grooved substrates on osteoblast behavior and extracellular matrix deposition. Biomaterials 2010; 31: 3307-16.

23. Mamalis AA, Silvestros SS. Analysis of osteoblastic gene expression in the early human mesenchymal cell response to a chemically modified implant surface: an in vitro study. Clinical oral implants research 2011; 22: 530-7.

24. Mendonca G, Mendonca DB, Aragao FJ et al. The combination of micron and nanotopography by $\mathrm{H}(2) \mathrm{SO}(4) / \mathrm{H}(2) \mathrm{O}(2)$ treatment and its effects on osteoblast-specific gene expression of hMSCs. Journal of biomedical materials research Part A 2010; 94: 169-79.

25. Owen TA, Aronow M, Shalhoub V et al. Progressive development of the rat osteoblast phenotype in vitro: reciprocal relationships in expression of genes associated with osteoblast proliferation and differentiation during formation of the bone extracellular matrix. Journal of cellular physiology 1990; 143: 420-30.

26. Boyan BD, Bonewald LF, Paschalis EP et al. Osteoblast-mediated mineral deposition in culture is dependent on surface microtopography. Calcified tissue international 2002; 71: 519-29. 


\section{LEGENDS}

Fig. 1. Titanium implants and disks without (a and d) and with (e and h) macroscopic grooves used in this study. The percentage bone-to-implant contact was calculated for the collar (red line) of the implant (b and f). The percentage of bone area was calculated for the rectangular area and inside the grooves (blue area) of the implant (c and g).

Fig. 2. Histological images of control (a and c) and experimental (b and d) implants stained with toluidine blue. New bone formation was observed at 6 weeks ( $a$ and b) and bone around the implant was matured at 24 weeks (c and d). Bone extension was observed within the grooves at 6weeks (b) and it is maintained entirely at 24 weeks (d).

Fig. 3. Bone-to-implant contact of control and experimental implants in rabbit tibiae $\left(^{*}: P<0.05\right)$.

Fig. 4. Bone area of control and test implants in rabbit tibiae $\left(^{*}: P<0.05\right)$.

Fig. 5. Alkaline phosphatase activity of titanium disks with or without macroscopic grooves $\left({ }^{*}: P<0.05\right)$ Fig. 6. Gene expression of human mesenchymal stem cells cultured on titanium disks with or without macroscopic grooves $\left({ }^{*}: P<0.05,{ }^{* *}: P<0.01\right)$. OPN: Osteopontin, OCN: Osteocalcin, Col1: Type 1 Collagen, ALP: alkaline phosphatase.

Table 1. Oligonucleotide sequences of forward $(F)$ and reverse $(R)$ primers used in real-time reversetranscription polymerase chain reaction for target and housekeeping genes 
Table 1. Oligonucleotide sequences of forward (F) and reverse (R) primers used in real-time reversetranscription polymerase chain reaction for target and housekeeping genes. Alkaline phosphatase $(A L P)$, an early marker of osteogenic differentiation, is found in high levels in cells that mineralize their extracellular matrix. Osteocalcin $(O C N)$, a late differentiation marker, is synthesized by osteoblasts and is an indicator of mineralized tissue. Osteopontin $(O P N)$ and type 1 collagen (Col1), osteoblastic differentiation markers, encode bone matrix proteins. 
Fig 1
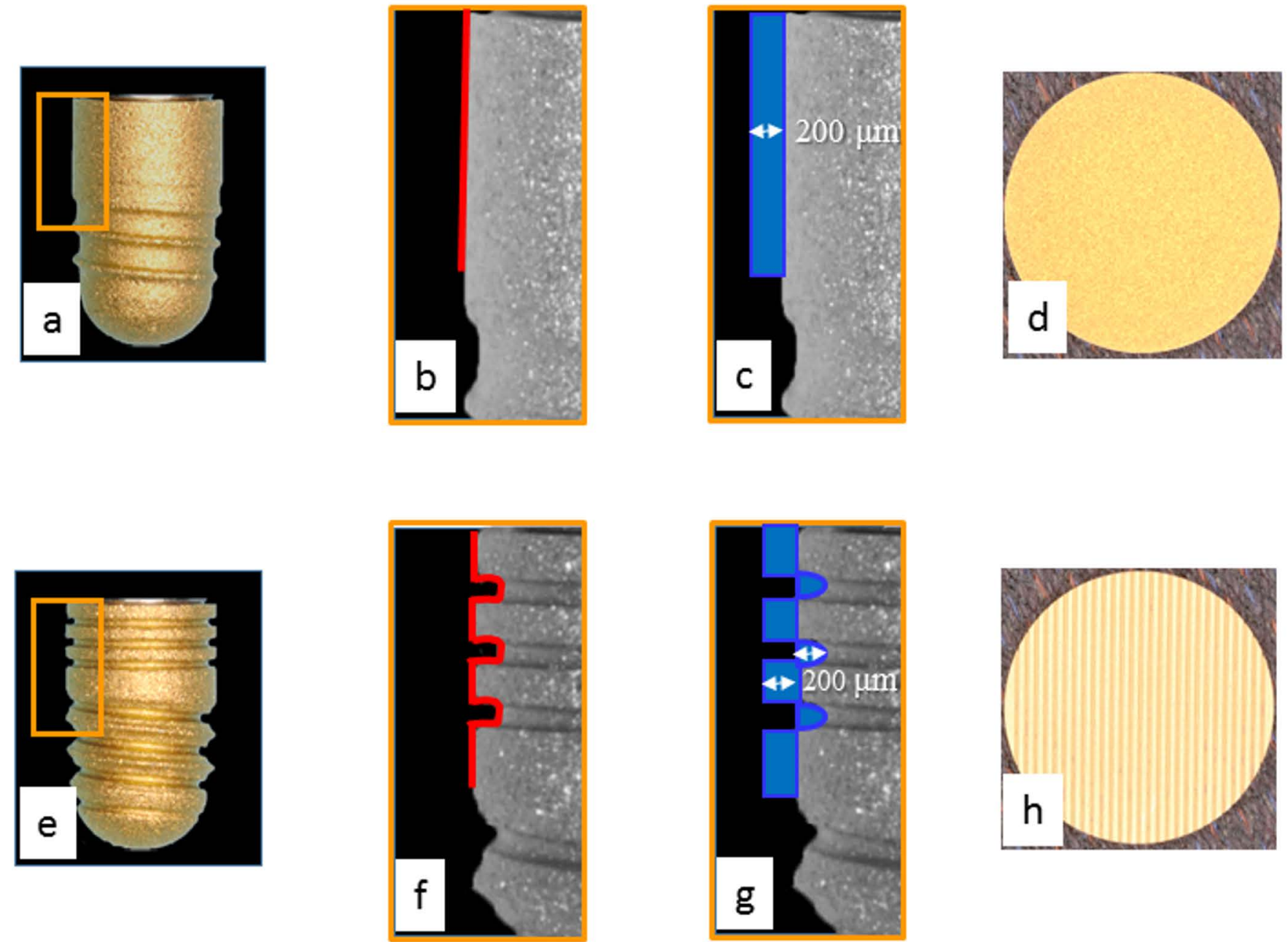
Fig 2
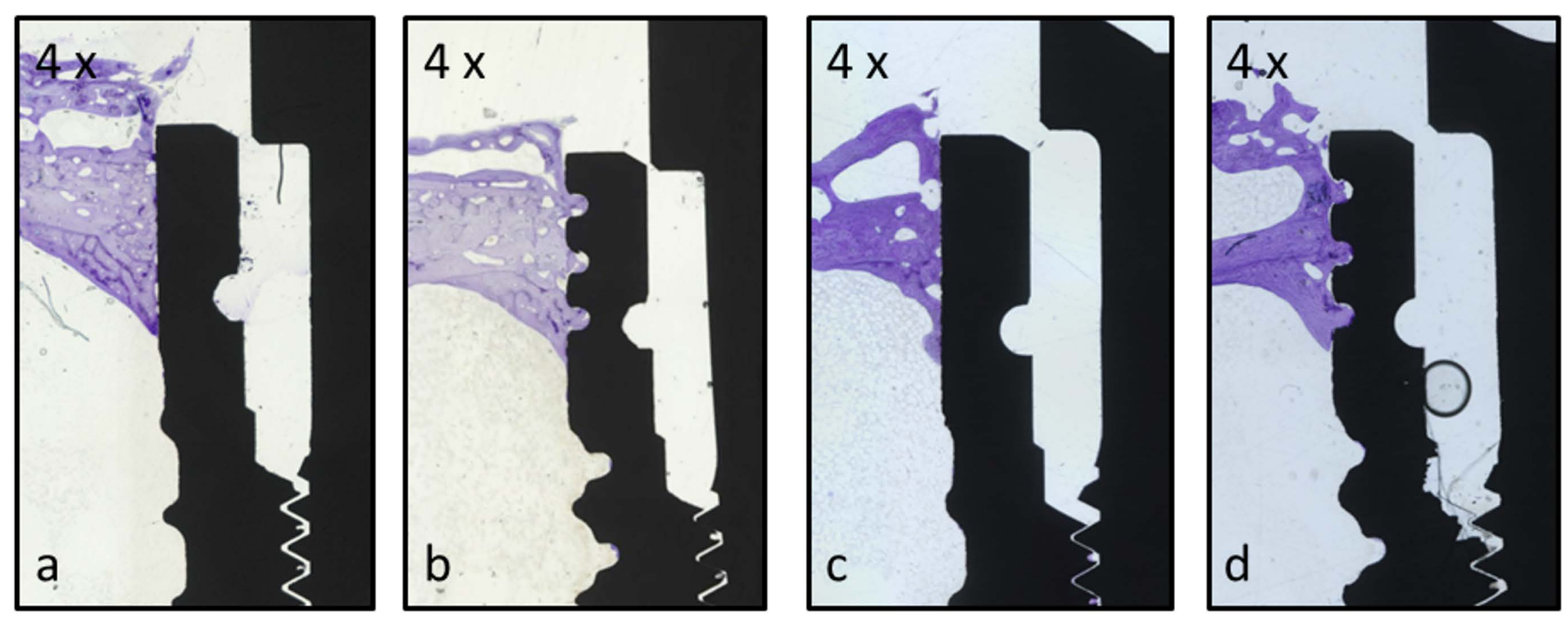
Fig 3
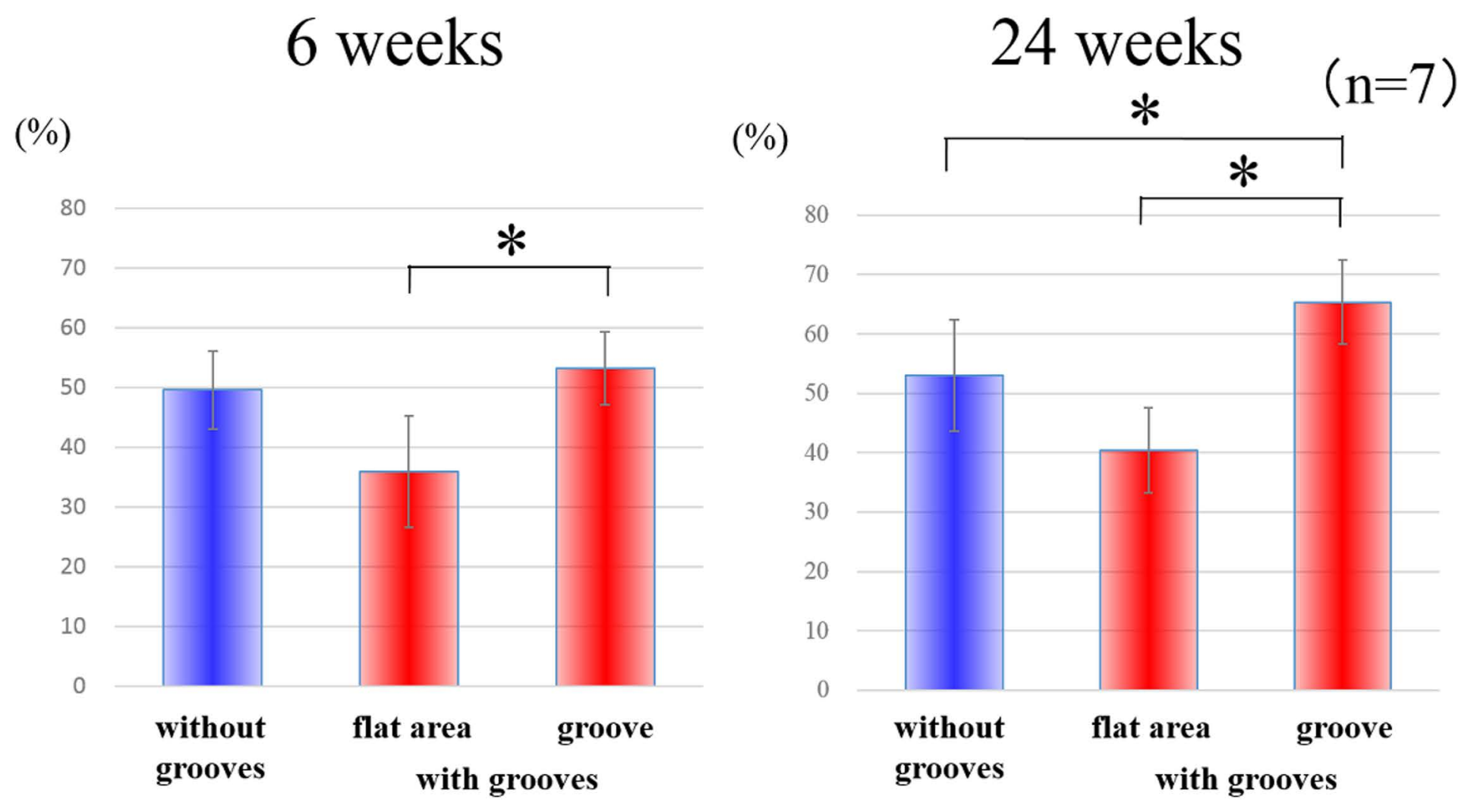
Fig 4
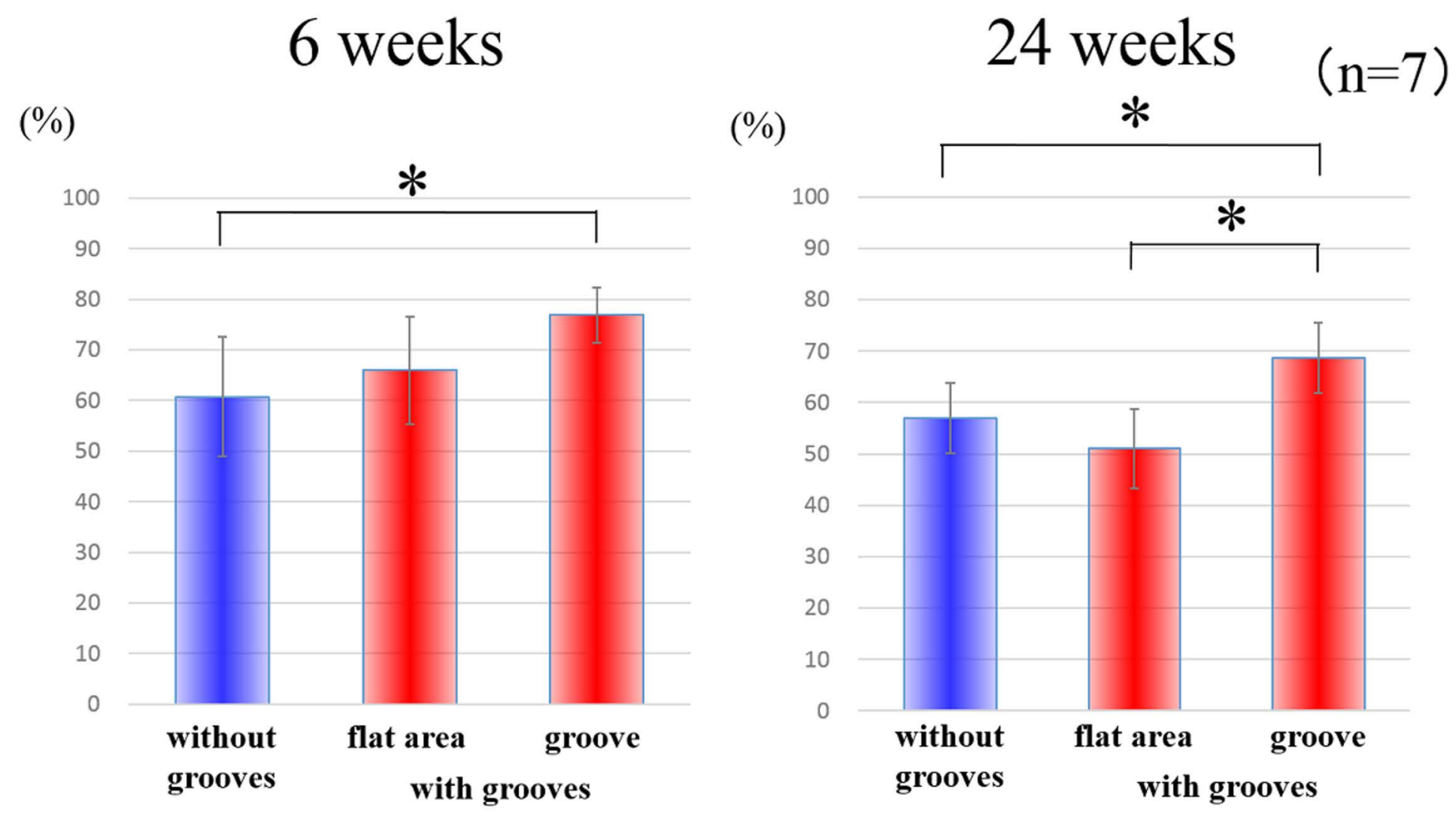
Fig 5

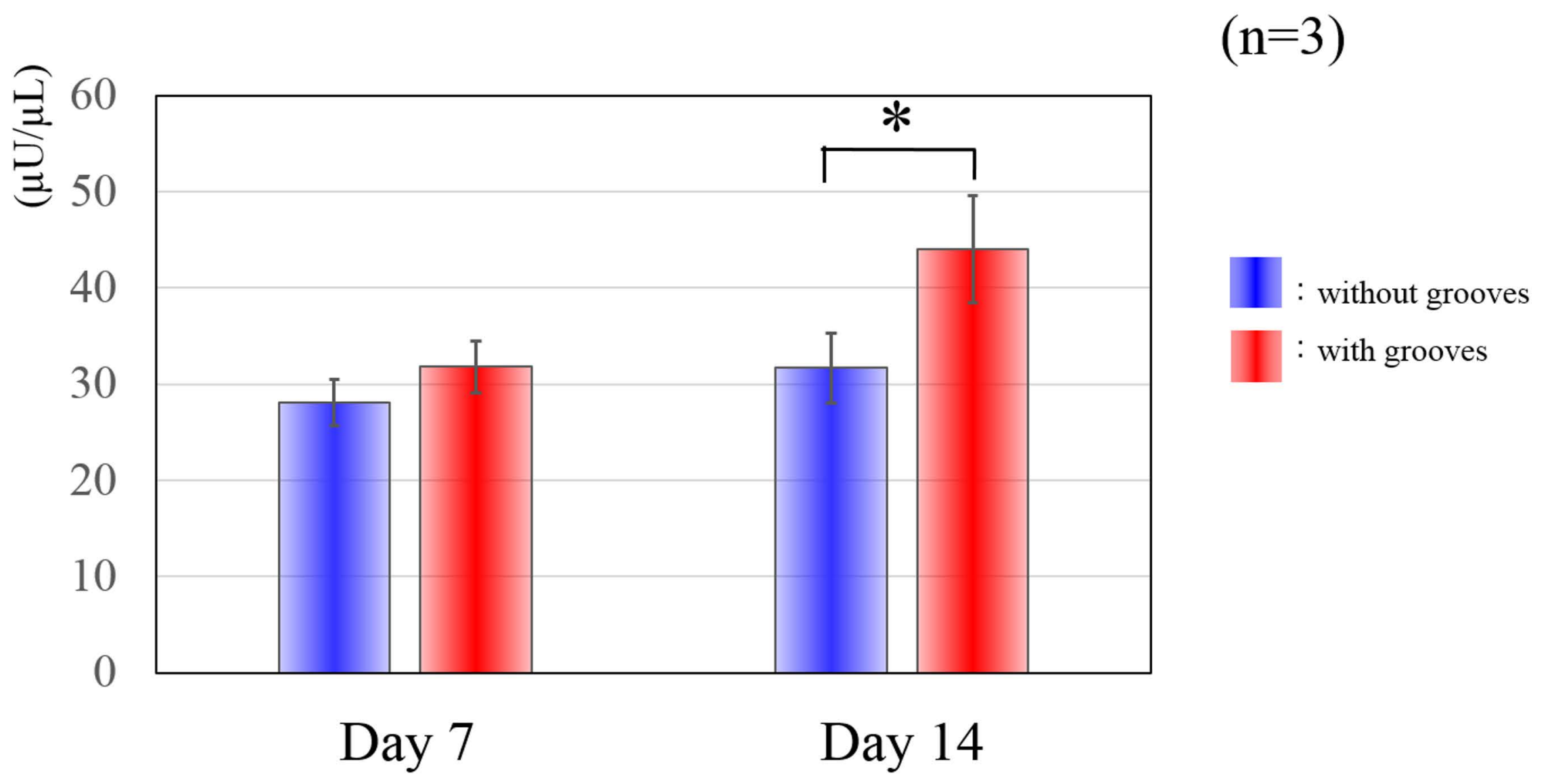


Fig 6
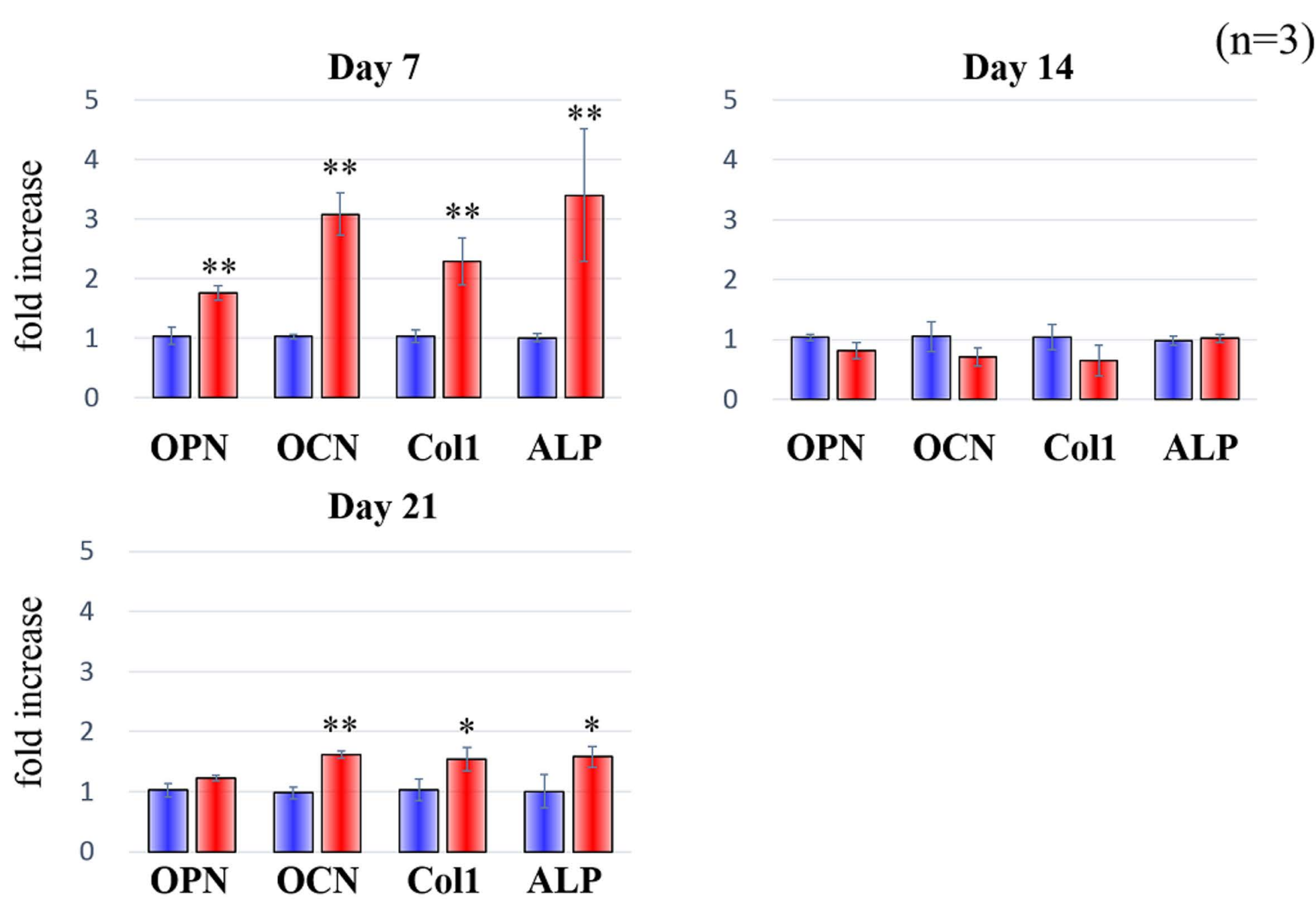


\section{Tables}

Table 1. Oligonucleotide sequences of forward (F) and reverse (R) primers used in real-time reversetranscription polymerase chain reaction for target and housekeeping genes

\begin{tabular}{lllc}
\multicolumn{1}{c}{ Gene } & & \multicolumn{1}{c}{ Primer sequence $\left(5^{\prime}\right.$ to $\left.3^{\prime}\right)$} & Tm Amplicon $\left({ }^{\circ} \mathrm{C}\right)$ \\
\hline Alkaline phosphatase & $\mathrm{F}$ & ACGTGGCTAAGAATGTCATC & 57.6 \\
Alkaline phosphatase & $\mathrm{R}$ & CTGGTAGGCGATGTCCTTA & 58.7 \\
Collagen 1 & $\mathrm{F}$ & TGACGAGACCAAGAACTG & 55.4 \\
Collagen 1 & $\mathrm{R}$ & CCATCCAAACCACTGAAACC & 62.5 \\
Osteocalcin & $\mathrm{F}$ & CATGAGAGCCCTCACA & 54.2 \\
Osteocalcin & $\mathrm{R}$ & AGAGCGACACCCTAGAC & 53.1 \\
Osteopontin & $\mathrm{F}$ & AGCCAGGACTCCATTGACTCGAAC & 69.1 \\
Osteopontin & $\mathrm{R}$ & GTTTCAGCACTCTGGTCATCCAGC & 68.7 \\
beta-ACTIN & $\mathrm{F}$ & AGCCATGTACGTTGCTA & 53.2 \\
beta-ACTIN & $\mathrm{R}$ & AGTCCGCCTAGAAGCA & 55.1 \\
\hline
\end{tabular}

